\title{
Advancing Environmental Mainstreaming in the Caribbean Region: The Role of Regional Institutions for Overcoming Barriers and Capacity Gaps
}

\section{Livia Bizikova ${ }^{1, *}$, Graciela Metternicht ${ }^{2}$ and Therese Yarde ${ }^{3}$}

1 International Institute for Sustainable Development (IISD), 1400-220 Laurier Street, Ottawa K1P 5Z9, ON, Canada

2 Institute of Environmental Studies (IES), University of New South Wales, Sydney NSW 2052, Australia; E-Mail: g.metternicht@unsw.edu.au

3 Caribbean Hub Capacity Building ACP-MEAs, CARICOM Secretariat, Turkeyen, P.O. Box 10827, Greater Georgetown, Guyana; E-Mail: Therese.Yarde@Caricom.org

* Author to whom correspondence should be addressed; E-Mail: lbizikova@iisd.ca; Tel.: +1-613-986-9319; Fax: +1-613-238-8515.

Academic Editor: Vincenzo Torretta

Received: 21 August 2015 / Accepted: 9 October 2015 / Published: 14 October 2015

\begin{abstract}
Environmental mainstreaming (EM) is a policy instrument to integrate environmental risks and opportunities into planning and implementation. A body of knowledge exists on identifying barriers for EM at the national level. This paper identifies contributions of regional institutions for improving capacities for EM at the national level, using the Caribbean region as a case study. The methodology adopted combines in-depth interviews with senior policy-makers and participatory workshops for medium- and junior-level staff of government agencies. Four barriers for EM are analyzed with specific roles for regional agencies, including weak leadership, insufficient science-policy linkages, deficits in quantity and quality of human resources, and institutional aspects. Research findings identify regional leadership as crucial to supporting the science-policy interface, to share data and knowledge across countries facing similar challenges, to provide assistance with national policy development for EM involving transboundary issues, and to ensure cross-sectoral perspectives in regional initiatives, especially those on economic development.
\end{abstract}

Keywords: environmental mainstreaming; policy integration; science and policy; SIDS; Caribbean region 


\section{Introduction}

Mainstreaming has been proposed as an effective tool to enhance policy development by increasing policy coherence, addressing trade-offs, and capturing the opportunities for synergistic results across social, economic, and environmental priorities [1]. In its early applications, mainstreaming the environment into development plans (such as poverty-reduction strategies) achieved mixed results that insufficiently addressed the needs of the poor and the contributions of the environment to their well-being [2].

More recently, mainstreaming has been regarded as an innovative instrument replacing stronger-and often ineffective-mechanisms of coordination [3]. The UN Environment Program, for instance, considers mainstreaming as a tool that can assist in highlighting linkages between development and the environment, identifying weaknesses in policy, legal and institutional frameworks for environmental sustainability - and prioritizing and planning for targeted actions, research, and policy to improve environmental management practices [4]. With a specific focus on environmental issues, environmental mainstreaming (EM) has been defined as "the informed inclusion of relevant environmental concerns into the decisions of institutions that drive national, local and sectoral development policy, rules, plans, investment and action" [5]. In this context, mainstreaming is understood as close to "integration" or "reciprocal mainstreaming" implying that context and the development aims are as important as the environmental aims, and that all three aspects should interact closely [5].

While mainstreaming has been advocated as an effective tool for policy integration, evidence shows it has largely failed to assist in connecting the environment with development priorities, and to effectively penetrate the policy agenda [4,6]. Research conducted over the last decade has identified challenges to advance mainstreaming at national and subnational levels [5-13]. A number of stumbling blocks to advancing EM have been cited, including weak leadership, difficult enabling environments, and lack of skills and human resources for proper engagement in the EM process. Barriers to providing salient science-based information in support of mainstreaming have also been underlined (Table 1).

Particularly at the leadership level, agencies that are often weak in terms of power and/or resources are the ones spearheading EM; thus, their efforts tend to be side-tracked in favor of stronger agencies or ministries, such as finance and economic development [1,14]. The electoral cycle also influences mainstreaming efforts. This is highlighted in research by Lasco et al. [11] and Sietz et al. [13] who noted that priority areas for implementation and resource allocation for national adaptation were modified after government changes. In terms of institutional rules and structures, it has been found that deep-rooted institutional structures hinder cross-sectoral collaboration and consultation, which are an important part of EM $[6,13,15,16]$.

Effective mainstreaming involves formal and informal mechanisms that enable policy-makers, researchers, and experts to interact and co-develop policies and actions [17]. Lack of support for collaboration is often coupled with insufficient staff capacities and skills for adopting an active role in policy development, collaboration, and communication with other agencies and stakeholders $[13,17]$. These institutional- and capacity-level barriers hamper the inclusion of information on environmental issues and trends, and outcomes from science-based assessments in policy design. In this context, further barriers can be identified in the form of narrowly focused science assessments lacking policy relevance for specific sectoral priorities [18]. 
Table 1. Mainstreaming experiences, related instruments, barriers, and capacity needs.

\begin{tabular}{|c|c|c|c|}
\hline Country/Region & $\begin{array}{c}\text { Mainstreaming } \\
\text { Type }\end{array}$ & Challenges/Barriers & $\begin{array}{c}\text { Capacity-Building Needs } \\
\text { Identified }\end{array}$ \\
\hline $\begin{array}{l}\text { European } \\
\text { Union-Regional } \\
{[12]}\end{array}$ & $\begin{array}{l}\text { Ecosystem service } \\
\text { (ES) into policy that } \\
\text { affects use of natural } \\
\text { resources }\end{array}$ & $\begin{array}{l}\text { Access to information and } \\
\text { knowledge (multi-scale mapping } \\
\text { approach where ecosystem services } \\
\text { are produced and the benefits are } \\
\text { appreciated) }\end{array}$ & $\begin{array}{l}\text { Methods to map, assess and value } \\
\text { ES at multiple spatial scales }\end{array}$ \\
\hline $\begin{array}{l}\text { Mozambique- } \\
\text { National [13] }\end{array}$ & $\begin{array}{l}\text { Climate adaptation } \\
\text { into development } \\
\text { assistance }\end{array}$ & $\begin{array}{l}\text { Lack of human resources within } \\
\text { relevant institutions } \\
\text { Insufficient data/information } \\
\text { availability } \\
\text { Weak data/information } \\
\text { management } \\
\text { Erosion of institutional memory } \\
\text { Lack of inter-institutional } \\
\text { coordination and communication } \\
\text { Gaps and overlaps in institutional } \\
\text { mandates } \\
\text { Short-term development goals } \\
\text { given a higher priority } \\
\text { Scarce adaptation funding } \\
\text { Lack of participation of local } \\
\text { communities }\end{array}$ & $\begin{array}{l}\text { Training of specialists within } \\
\text { environmental units to identify } \\
\text { sector-specific effects of climate } \\
\text { change, and to develop adaptation } \\
\text { strategies } \\
\text { Data availability and management } \\
\text { Enhanced understanding of } \\
\text { procedural, organizational and } \\
\text { normative aspects of mainstreaming } \\
\text { Strengthening environmental units } \\
\text { to foster institutional coordination }\end{array}$ \\
\hline $\begin{array}{l}\text { Philippines- } \\
\text { National [11] }\end{array}$ & $\begin{array}{l}\text { Climate change } \\
\text { adaptation into } \\
\text { national development } \\
\text { policies and plans }\end{array}$ & $\begin{array}{l}\text { Lack of knowledge and } \\
\text { understanding of climate change } \\
\text { Lack of political will } \\
\text { Lack of funding } \\
\text { Insufficient advocacy by NGOs } \\
\text { and others }\end{array}$ & $\begin{array}{l}\text { Support from researchers involved } \\
\text { in climate change } \\
\text { Recognition that climate change } \\
\text { policies will provide benefits to the } \\
\text { country } \\
\text { Understanding by policy-makers } \\
\text { that taking care of the environment } \\
\text { is important }\end{array}$ \\
\hline $\begin{array}{l}\text { Australia- } \\
\text { National [17] }\end{array}$ & $\begin{array}{l}\text { Whole-government } \\
\text { approach to recognize } \\
\text { interdependences } \\
\text { between policy areas } \\
\text { in systematically }\end{array}$ & $\begin{array}{l}\text { Limited involvement of non- } \\
\text { government actors in policy design } \\
\text { Lack of performance-based } \\
\text { outcomes of integrated initiatives }\end{array}$ & $\begin{array}{l}\text { Support on cross-sectoral policy } \\
\text { integration in an adaptable manner } \\
\text { Capacity needs to ensure effective } \\
\text { integration of aboriginal issues in } \\
\text { policy design }\end{array}$ \\
\hline $\begin{array}{l}\text { CARICOM } \\
\text { (Caribbean } \\
\text { Community) } \\
\text { Regional with } \\
\text { national }[8,19]\end{array}$ & $\begin{array}{l}\text { Climate change } \\
\text { adaptation into } \\
\text { national and sectoral } \\
\text { planning and policies } \\
\text { (MACC project) }\end{array}$ & $\begin{array}{l}\text { Lack of risk-management approach } \\
\text { to climate change adaptation } \\
\text { Lack of regional technical capacity } \\
\text { Lack of adaptation strategies in the } \\
\text { water and health sectors }\end{array}$ & $\begin{array}{l}\text { Capacity to identify climate change } \\
\text { risks } \\
\text { Capacity to reduce vulnerability to } \\
\text { climate change } \\
\text { Capacity to access and utilize } \\
\text { resources to minimize the costs of } \\
\text { climate change }\end{array}$ \\
\hline
\end{tabular}


Table 1. Cont.

\begin{tabular}{|c|c|c|c|}
\hline Country/Region & $\begin{array}{c}\text { Mainstreaming } \\
\text { Type }\end{array}$ & Challenges/Barriers & $\begin{array}{c}\text { Capacity-Building Needs } \\
\text { Identified }\end{array}$ \\
\hline $\begin{array}{l}\text { Caribbean } \\
\text { region-National } \\
{[10]}\end{array}$ & $\begin{array}{l}\text { Survey on } \\
\text { experiences with EM } \\
\text { in Barbados, Jamaica, } \\
\text { Trinidad and Tobago }\end{array}$ & $\begin{array}{l}\text { Lack of capacities of policy-makers } \\
\text { to guide and review environmental } \\
\text { integration into planning } \\
\text { Lack of long-term monitoring data }\end{array}$ & $\begin{array}{l}\text { Improved education of policy- } \\
\text { makers in environmental } \\
\text { management } \\
\text { Skills and institutional support for } \\
\text { collaboration } \\
\text { Improve science capacities to } \\
\text { provide inputs for EM }\end{array}$ \\
\hline Global [5] & $\begin{array}{l}\text { Issues Paper based on } \\
\text { a } 12 \text { country survey } \\
\text { and global review }\end{array}$ & $\begin{array}{l}\text { The prevailing development } \\
\text { paradigm, which treats environment } \\
\text { as an institutional and economic } \\
\text { "externality" } \\
\text { Lack of data, skills and institutional } \\
\text { capacity to work on EM } \\
\text { Weak EM initiatives to act as a } \\
\text { precedent } \\
\text { Lack of political will }\end{array}$ & $\begin{array}{l}\text { Supporting national planning for } \\
\text { including EM in their priorities } \\
\text { Supporting broad collaboration } \\
\text { between government and } \\
\text { non-governmental agencies } \\
\text { To improve transparency on used } \\
\text { data, processes and decisions made }\end{array}$ \\
\hline
\end{tabular}

* Antigua and Barbuda, the Bahamas, Barbados, Belize, Dominica, Grenada, Guyana, Jamaica, Saint Lucia, St. Kitts and Nevis, St. Vincent, and Trinidad and Tobago.

While the overview of barriers for mainstreaming cover a range of national and subnational challenges, research [13,20-22] emphasizes the importance of considering support from regional level to subnational levels to improve EM capacities. On the role of regional support, Integra [18] stressed (based on Australian experience) that regional networks can assist decision-makers in creating policies and strategies considering EM, and in designing administrative structures and processes to implement such policies. Given this evidence on the benefits of regional support, and commonality of documented barriers at the national and subnational levels across countries, an opportunity arises for a potentially larger role for regional coordination and support for EM at the national level. Against this background, this paper assesses context-specific knowledge and experiences for greater engagement of regional organizations, and the role of multi-level coordination from regional to local in advancing EM. It presents critical insights into the comprehensive support that regional agencies can provide to address barriers to mainstreaming, and it discusses opportunities for promoting a (more) effective approach to $\mathrm{EM}$ at the national and sub-national levels. In-depth exploration of support from regional to national levels is facilitated by a critical review of current experiences, capacities, barriers and potential roles of regional agencies in the Small Island Development States of the Caribbean (Caribbean SIDS). These countries face a number of environmental challenges, with their economies heavily dependent on natural resources for their major industries - tourism, fisheries and agriculture [6]. Furthermore, anecdotal and empirical evidence suggests that weak institutional capacity is a common problem among Caribbean countries [23] including limited capacity to implement and enforce existing legislation, poor institutional arrangements, and limited experience in working with cross-sectoral data and information $[4,6,10,24]$.

The next section describes the methodological approach to data collection for identifying specific experiences and capacity needs of policy-makers in the Caribbean SIDS region with EM. Sections Four 
and Five present the results and discussion focused on key types of barriers to EM and on the role of regional institutions. The conclusions summarize future research needs for advancing EM centered on regional leadership.

\section{Method}

\subsection{Scoping Phase and Setting the Agenda}

The Caribbean SIDS face environmental challenges that include the degradation of coastal and marine biodiversity, worsening fresh water quality, environmental pollution, and increased soil degradation [4,25-28]. Like other SIDS, they also face a number of socioeconomic challenges, including heavy dependence upon the natural resource base (agriculture, forestry, fishing, tourism, mining, and light manufacturing); susceptibility to the vagaries of international trade; lack of economies of scale; high transportation and communication costs; extreme vulnerability to natural disasters; scarce land resources; and ever-increasing pressures on coastal and marine environments [28].

The heavy economic dependence on natural resources for their major industries (tourism, fisheries, and agriculture) generates a strong relationship between a healthy environment and socioeconomic development [27,28]. At the same time, these economic sectors can act as environmental stressors [24,27,28]. Tourism is a case in point; annual tourist numbers of more than 75 million overnight stays are estimated to generate as much as 166 million tonnes of waste in the Caribbean [26]. This complex relationship between the environment and the economy requires implementing more effective measures to halt and reverse the region's negative environmental trends [8,9,27]. A key challenge in this regard is to go beyond the sole improvement of environmental management and policy, and mainstream environmental considerations into specific, large-scale sectoral socioeconomic and development policies, strategies, initiatives, and investments. Furthermore, a limited pool of skilled human resources exists to perform the vital roles of the public service [23], and that needs to be taken into account when aiming to advance EM.

This research was undertaken in the Small Island Development States of the Caribbean (Caribbean SIDS), within the framework of a Program for Capacity-Building in the African, Caribbean and Pacific (ACP) countries commissioned by the European Commission. While the overall objective of the program was to enhance countries' capacity to improve management of their environment and natural resources, one aspect of the program focused on how to improve mainstreaming of Multilateral Environmental Agreements (MEAs) into development strategies and policies. Multi-stakeholder engagement undertaken as part of the program evidenced that previous capacity building on mainstreaming focused on the national and sub-national levels, with regional organizations only acting as project coordinators, rather than engaging in a more active role in advancing mainstreaming. Furthermore, key stakeholders, including representatives of regional and international agencies, such as the Caribbean Community (CARICOM), the UN Environment Program (UNEP), the Organization of Eastern Caribbean States (OECS), and senior decision-makers of the region stressed the need for policy-makers beyond the environmental realm to be engaged in mainstreaming. These regional institutions are active in reaching out to national governments in the region on initiatives related to trade, economic development, and transboundary issues with high importance for environmental mainstreaming. 
Based on the outcomes of these initial consultations, a sequence of methods was used to gain insights from senior government officials of the Caribbean engaged in decision making, as well as bureaucrats in different government and non-governmental agencies engaged in preparing inputs for decision-making and developing sectoral and cross-sectoral strategies, plans and policies. An overview of the methodological approach is presented in Table 2.

Table 2. Overview of the methods applied for data and information gathering.

\begin{tabular}{|c|c|c|}
\hline Methods & Overview of the method/approach & Purpose \\
\hline Initial scoping & $\begin{array}{l}\text { Meetings with project leads and key regional agencies } \\
\text { and decision-makers }\end{array}$ & $\begin{array}{l}\text { To identify the focus of the research that is relevant } \\
\text { for policy-makers in the Caribbean region. } \\
\text { Review steps in the project and planned means of } \\
\text { implementation. } \\
\text { To recommend senior decision-makers in the } \\
\text { Caribbean countries for the interviews and to be } \\
\text { involved in the next phases of the project. }\end{array}$ \\
\hline $\begin{array}{l}\text { Interviews } \\
\text { with senior } \\
\text { government } \\
\text { officials }\end{array}$ & $\begin{array}{l}\text { Semi-structured interviews. } \\
\text { The interviews were conducted from August to } \\
\text { November 2010; each in-depth interview lasted from } \\
45 \text { to } 75 \text { min. } \\
29 \text { interviews with respondents from eight countries } \\
\text { were conducted } \\
\text { The interviews were conducted in English. }\end{array}$ & $\begin{array}{l}\text { To elicit views, barriers and capacity needs from } \\
\text { senior decision-makers especially at the leadership } \\
\text { levels and on potential effective. } \\
\text { To secure support and identify contacts for the junior } \\
\text { policy-makes for the participatory workshops. }\end{array}$ \\
\hline $\begin{array}{l}\text { Participatory } \\
\text { workshops }\end{array}$ & $\begin{array}{l}\text { The workshops combined presentations, small group } \\
\text { work, plenary discussions and working with handouts } \\
\text { of published research relevant to EM. Three- to } \\
\text { four-day workshops were conducted, with attendance } \\
\text { ranging from } 15 \text { to } 34 \text { participants (for a total of } \\
119 \text { participants). } \\
\text { The workshops were held in English with groups also } \\
\text { communicating in Spanish. } \\
\text { Two note takers recorded the plenary discussion and } \\
\text { there were additional note takers during the group work } \\
\text { (one per each group). } \\
\text { Evaluation forms completed at the end of the } \\
\text { workshop; total } 106 \text { forms were collected. }\end{array}$ & $\begin{array}{l}\text { The workshops provided a space to discuss } \\
\text { experiences of junior policy-makers and } \\
\text { government officials representing different sectors, } \\
\text { and to explore barriers and capacity needs for } \\
\text { mainstreaming across sectors/countries. } \\
\text { Individual evaluation forms were completed to gain } \\
\text { insights on each participant's views on the } \\
\text { workshop process and capacity needs and gaps. }\end{array}$ \\
\hline $\begin{array}{l}\text { Data } \\
\text { processing }\end{array}$ & $\begin{array}{l}\text { Transcripts were developed from the interviews and the } \\
\text { workshops. } \\
\text { Coding system using NVivo (QSR International) was } \\
\text { used to process the transcripts. } \\
\text { Basic statistical analyses using was used to process the } \\
\text { evaluation forms. }\end{array}$ & $\begin{array}{l}\text { To identify key trends from the interviews and } \\
\text { participatory workshops. } \\
\text { To prioritize mainstreaming gaps and capacity } \\
\text { needs by using scoring and statistical analyses } \\
\text { using Microsoft Excel. }\end{array}$ \\
\hline
\end{tabular}




\subsection{Interviews with Senior Government Officials}

Semi-structured interviews with senior government officials of six Caribbean countries (St. Lucia, Belize, Guyana, Barbados, Bahamas, Jamaica, St. Vincent and the Grenadines, and Suriname) were conducted to understand specific leadership challenges and capacity-building needs in the context of EM at national and regional levels. Snowball sampling [29] was used to identify respondents based on an initial set of stakeholders. The sampling strategy identified two major groups of stakeholders: (1) senior policy-makers, such as directors of key ministries/departments dealing with the environment, economic development, tourism and agriculture, and (2) leaders of major regional organizations involved in natural resource management, sustainable development, tourism, agriculture, and economic development (e.g., UNEP offices in the region, the CARICOM, and the OECS).

The hypothesis guiding these interviews was that senior government officials can provide key insights on the role on regional institutions and national level engagement in mainstreaming across ministries and sectors. The outcomes of these interviews were used to frame key areas that needed discussion with policy-makers during the workshops: exploring institutional structures and opportunities for collaboration; interactions between science and policy to identify if they could address needs expressed by senior policy-makers; and resources, needs, and knowledge gaps of junior policy-makers to supply inputs indicated by senior policy-makers. These interviews were also an effective instrument for making contact with policy-makers for the next phase of the research.

\subsection{Participatory Workshops in the Caribbean Region}

Four participatory workshops (Table 3) were conducted bringing together medium and junior policy-makers from the region. The hypothesis guiding these workshops was that the participants can provide detailed information and knowledge on best practices on mainstreaming, and identify gaps and capacity needs at national and regional levels. Regional and national-level workshops were delivered to understand national capacities and needs and to explore the role of regional support for addressing such needs across the region. In terms of the workshop structure, [4,5,8,15,30] suggest discussing mainstreaming first at the level of linkages between high-level national development goals and priorities relevant to the region or country, and then focusing on specific sectors such as tourism, agriculture, poverty, and development, to identify approaches, barriers and capacity needs. This means workshop design and implementation need to be flexible to account for the diverse views and values of stakeholders, as well as varying levels of experience and knowledge [26,27,31]. The approach also needs to foster active sharing and peer-to-peer learning among stakeholders to identify key barriers, challenges and sharing practices with experts across different sectors and regions.

The four workshops conducted in the Caribbean took place in Suriname (in 2011); St. Vincent and the Grenadines (2012); St. Lucia (2013); and Belize (2013) (Table 3). Initial discussions during the project framing phase pointed to the importance of engaging medium- and junior-level policy-makers with diverse sectoral involvement such as agriculture, tourism, spatial planning, and economic development, as these policy-makers can play crucial roles in EM. After each workshop, evaluations were conducted to gather participant feedback. A total of 106 evaluation forms were collected to gain 
insights into the key questions on EM discussed in this paper. A brief report summarizing the results was prepared after each workshop and reviewed by all participants.

Table 3. Overview of the participatory workshops.

\begin{tabular}{|c|c|c|c|c|}
\hline Location & Suriname & $\begin{array}{l}\text { St. Vincent and the } \\
\text { Grenadines }\end{array}$ & St. Lucia & Belize \\
\hline Scale & Regional & National & Regional & National \\
\hline Key focus & $\begin{array}{l}\text { Mainstreaming into } \\
\text { sectors prioritized by } \\
\text { the participants }\end{array}$ & $\begin{array}{l}\text { Mainstreaming } \\
\text { environment into } \\
\text { poverty reduction }\end{array}$ & $\begin{array}{l}\text { Institutional aspect of } \\
\text { mainstreaming }\end{array}$ & $\begin{array}{l}\text { Mainstreaming into } \\
\text { national development } \\
\text { planning }\end{array}$ \\
\hline Sectors & $\begin{array}{l}\text { Agriculture, forestry, } \\
\text { fisheries, tourism }\end{array}$ & $\begin{array}{l}\text { Agriculture, forestry, } \\
\text { fisheries, tourism }\end{array}$ & $\begin{array}{l}\text { Forestry, fisheries, } \\
\text { tourism, trade }\end{array}$ & $\begin{array}{l}\text { Tourism, agriculture, } \\
\text { urban development }\end{array}$ \\
\hline $\begin{array}{l}\text { Number of } \\
\text { participants }\end{array}$ & 41 & 17 & 38 & 23 \\
\hline $\begin{array}{l}\text { Participants } \\
\text { affiliations }\end{array}$ & $\begin{array}{l}30 \% \text { ministries of } \\
\text { agriculture, fisheries, } \\
\text { forestry } \\
25 \% \text { ministries and } \\
\text { agencies of } \\
\text { environmental } \\
\text { protection and health } \\
20 \% \text { ministries and } \\
\text { agencies of economy, } \\
\text { transport and planning } \\
15 \% \text { ministries and } \\
\text { agencies of tourism and } \\
\text { recreation } \\
10 \% \text { ministries and } \\
\text { agencies of health and } \\
\text { public safety }\end{array}$ & $\begin{array}{l}30 \% \text { ministries of } \\
\text { agriculture, fisheries, } \\
\text { forestry } \\
20 \% \text { ministries and } \\
\text { agencies of } \\
\text { environmental } \\
\text { protection and health } \\
20 \% \text { ministries of } \\
\text { tourism and recreation } \\
10 \% \text { ministries of } \\
\text { transport and urban } \\
\text { planning } \\
10 \% \text { non-governmental } \\
\text { agencies }\end{array}$ & $\begin{array}{l}25 \% \text { ministries of } \\
\text { agriculture, fisheries, } \\
\text { forestry } \\
30 \% \text { ministries and } \\
\text { agencies of } \\
\text { environmental } \\
\text { protection and health } \\
20 \% \text { ministries and } \\
\text { agencies of tourism } \\
\text { and recreation } \\
15 \% \text { ministries and } \\
\text { agencies of } \\
\text { economy, transport } \\
\text { and planning } \\
10 \% \text { ministries and } \\
\text { agencies of economic } \\
\text { development }\end{array}$ & $\begin{array}{l}20 \% \text { ministries of } \\
\text { agriculture, fisheries, } \\
\text { forestry } \\
20 \% \text { ministries and } \\
\text { agencies of } \\
\text { environmental } \\
\text { protection and health } \\
20 \% \text { ministries of } \\
\text { tourism and recreation } \\
20 \% \text { ministries of } \\
\text { transport and urban } \\
\text { planning } \\
10 \% \text { non-governmental } \\
\text { agencies }\end{array}$ \\
\hline
\end{tabular}

\subsection{Data Processing}

Transcripts of the interviews and workshops and the evaluation forms were used to analyze and interpret results. A simple coding system [32] reflecting the framework categories and key themes within the research questions were used to organize results from the interviews and workshops. NVivo (QSR International) was used to this end. A total of 18 major issues (approximately four to five issues per barrier type identified in the literature review of Section 1) were identified, and used to discern key similarities and differences in capacity-building needs for EM (Table 4). To further explore the importance of the identified barriers, key scores given by medium- and junior-level policy-makers to barriers listed during the interviews and the workshops were processed using basic statistical analyses. These scores were collected at the end of each workshop, as part of the evaluation forms. Respondents scored the barriers from one to four; four being the most relevant item. Basic statistical analysis of these 
scores was done using Microsoft Excel, calculating sums of total scores, average, standard deviation, and median (Table 5).

Table 4. Barriers to EM in the Caribbean region, as perceived by policy-makers, and reasons frequently cited by policy-makers participating in the workshops.

\section{Barriers and issues identified}

(A1) Directors and senior leaders lack arguments, data and information to enter into the crosssectoral debate to support EM.

(A2) Lack of understanding of the importance of cross-sectoral planning/collaborations at the senior decision-making level

(A3) Economic development and related issues are more important than EM for getting elected or have a term renewed in Office

(A4) Limited interaction with staff to get information on EM and related issues

(A5) Lack of resources and capacities to follow through on issues such as EM

(B1) Lack of credible information on economic and environmental issues in accessible form to

for inputs in the policy process)

\section{Reasons cited by policy-makers}

Lack of monitoring to illustrate impacts of development on the environment to other ministers and sectors; cost-benefit information is needed to illustrate costs of not taking the environment into account; limited interest in EM at the regional level to build support at the national level; environmental issues are discussed in the context of other important issues, but they do not lead the development debate; lack of practical knowledge and awareness needed for supporting mainstreaming efforts at the senior decision-making level.

Limited opportunities and time to devote to efforts on integrated planning to support EM; such planning does not seem to be recognized as important compared to other pressing issues; lack of good examples on integration/cross-sectoral planning in the region are a challenge as well.

Economic development, employment and infrastructure are seen as more important than the environment; overall uncertainty on benefits and challenges on taking a lead on environmental issues as compared to development priorities.

Lack of timely and relevant information on EM to support senior policy-makers in meetings, negotiations; insufficient time to interact with staff beyond key focus of the specific office/department (and EM is not the key focus)

Even if we bring up this issue with other ministries, it is often dropped/minimized in the next phases of plan development, strategy review; EM is often neglected at the later stages of the planning process, especially when policies and regulations are developed; in some countries, there are laws that integrate the environment, but they are not operationalized to a larger extent at the policy and implementation levels.

Assessments of environment and environmental impacts often do not include current economic and development activities plans and efforts, so it is hard for the policymakers to make the integration; data on environmental and development issues are published separately and it is challenging to link causes and impacts between development and environment.

Environmental assessments are written in jargon without a summary for policymakers; research outcomes do not provide recommendations for policy, planning to identify actions for EM and related policy development.

Science outcomes take a long time to develop and often are done too late for the planning process; science outcomes often need to be peer reviewed, which takes a long time, and then we miss the legislative window for making changes; many of the science inputs come in the form of models and trends in narrowly specified systems that are not relevant for highlighting implications for decision making.

(B4) Lack of specific monitoring and data to illustrate trends, impacts on development on environment
Lack of structured data-sharing across the region to link lessons learned from different places and cases to illustrate environmental impacts and changes with monitoring data 
Table 4. Cont.

\begin{tabular}{|c|c|c|}
\hline \multicolumn{2}{|r|}{ Barriers and issues identified } & Reasons cited by policy-makers \\
\hline \multirow{4}{*}{ 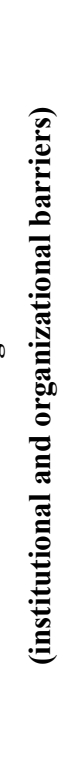 } & $\begin{array}{l}\text { (C1) Hard to reach directors and } \\
\text { senior bureaucrats from other } \\
\text { departments to engage them in } \\
\text { cross-sectoral collaboration }\end{array}$ & $\begin{array}{l}\text { Regular meetings are narrowly focused on staff mandates and tasks; limited number } \\
\text { of regular meetings; rather ad-hoc meetings. }\end{array}$ \\
\hline & $\begin{array}{l}\text { (C2) Lack of performance } \\
\text { measures for staff/policy-makers } \\
\text { rewarding collaboration }\end{array}$ & $\begin{array}{l}\text { Collaboration and reaching out to other agencies and policy-makers is not part of the } \\
\text { staff's evaluation; it is unclear if collaboration with other policy-makers helps in } \\
\text { performance review; there are no specific requirements for collaboration across } \\
\text { sectors/departments. }\end{array}$ \\
\hline & $\begin{array}{l}\text { (C3) Competition between } \\
\text { departments or agencies }\end{array}$ & $\begin{array}{l}\text { Concern about losing leadership on issue/file if more in-depth collaboration occurs; } \\
\text { there are no clear practices about how to share files when multiple departments are } \\
\text { involved; once a department leads an issue, it is important, especially for the senior } \\
\text { policy-makers, to maintain this leadership. }\end{array}$ \\
\hline & $\begin{array}{l}\text { (C4) Concerns that collaboration } \\
\text { will require funding splitting } \\
\text { between collaborators }\end{array}$ & $\begin{array}{l}\text { Leadership on issues usually has budgetary implications presently and/or in the } \\
\text { future, thus maintaining the specific leadership position is critical. }\end{array}$ \\
\hline \multirow{4}{*}{ 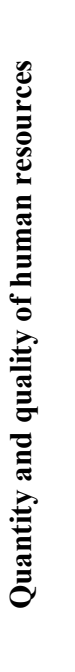 } & $\begin{array}{l}\text { (D1) Lack of time because of } \\
\text { other work/duties }\end{array}$ & $\begin{array}{l}\text { Our current work duties increasingly fill up our working hours and there is no time } \\
\text { for engaging substantively on collaborative efforts; informal engagement is more } \\
\text { relevant, as it can be better adjusted to time availability, but that tends to be dropped } \\
\text { when there is too much work. }\end{array}$ \\
\hline & $\begin{array}{l}\text { (D2) Lack of skills to effectively } \\
\text { collaborate with other sectors }\end{array}$ & $\begin{array}{l}\text { Medium and junior staff lack experience with leading larger meetings and } \\
\text { consultations/collaborations processes; they lack skills to deal with tensions when } \\
\text { teams at different levels are collaborating. }\end{array}$ \\
\hline & $\begin{array}{l}\text { (D3) Lack of information, } \\
\text { knowledge to participate in a } \\
\text { meaningful way }\end{array}$ & $\begin{array}{l}\text { Lack of clarity on the effective inputs and outputs of the collaborative process; lack } \\
\text { of understanding on available data, research and policy needs for other departments, } \\
\text { so that collaboration would be necessary. }\end{array}$ \\
\hline & $\begin{array}{l}\text { (D4) Lack of guidelines within } \\
\text { departments or agencies on modes } \\
\text { of collaboration }\end{array}$ & $\begin{array}{l}\text { Staff are unsure of approaching other departments mostly because of potential } \\
\text { funding implications; lack of clarity on who and how to approach within their own } \\
\text { and other departments to initiate collaboration. }\end{array}$ \\
\hline
\end{tabular}

Table 5. Scoring given by medium- and junior-level policy-makers to the barriers listed in Table 4 scores ranged from one to four; four being the most relevant item.

\begin{tabular}{ccccc}
\hline Specific barriers & Sum & Average & Standard deviations & Median \\
\hline A1 & 205 & 1.95 & 0.76 & 2 \\
A2 & 236 & 2.25 & 0.90 & 2 \\
A3 & 311 & 3.10 & 0.77 & 3 \\
A4 & 212 & 2.02 & 0.75 & 2 \\
A5 & 358 & 3.41 & 0.65 & 3 \\
B1 & 219 & 2.09 & 0.77 & 2 \\
B2 & 340 & 3.24 & 0.71 & 3 \\
B3 & 264 & 2.51 & 0.94 & 2 \\
B4 & 318 & 3.03 & 0.74 & 3 \\
B5 & 316 & 3.01 & 0.85 & 3 \\
C1 & 237 & 2.26 & 0.78 & 2 \\
\hline
\end{tabular}


Table 5. Cont.

\begin{tabular}{ccccc}
\hline Specific barriers & Sum & Average & Standard deviations & Median \\
\hline C2 & 344 & 3.28 & 0.70 & 3 \\
C3 & 349 & 3.32 & 0.69 & 3 \\
C4 & 347 & 3.30 & 0.77 & 3 \\
D1 & 347 & 3.30 & 0.71 & 3 \\
D2 & 348 & 3.31 & 0.67 & 3 \\
D3 & 234 & 2.23 & 0.85 & 2 \\
D4 & 347 & 3.30 & 0.79 & 4 \\
\hline
\end{tabular}

The highest scores are highlighted in grey ( $\mathrm{n}=106$; sum $=$ number of responses).

\section{Results from Policy-Makers: Detailed Accounts of Barriers for Environmental Mainstreaming at the National Levels and Implications for Regional Support}

This section presents the range of barriers for EM that policy-makers put forward during the interviews and the workshops, grouped according to main categories of barriers identified in the literature. Within these categories, we specify the role of national and regional institutions. We also present the frequency of specific barriers as they were reported during this research (Table 5), as well as specific examples listed by the participants (Table 4).

\subsection{Leadership Barriers for Advancing EM}

Most participants perceived the lack of political will at the national level as one of the major barriers for mainstreaming. Participants also indicated that, in some cases, environmental challenges superseded economic priorities because of the worsening impacts of economic development on environment and related severe consequences, such as serious localized water pollution, limited water availability, increasing debris in the oceans and seas, and coastal land degradation. At the regional level, participants felt the role of regional institutions has weakened over the last decade, although they still possess strong leadership potential. Key regional leadership in the context of EM requires agencies with regional mandates emphasize the importance of EM at regional and national levels through such mechanisms as regional treaties and national development plans. At the same time, there needs to be a focus on EM for specific issues relevant to national economies (such as tourism development, poverty reduction, and fisheries); these can serve as vehicles to advance EM in this specific context.

Most medium- and junior-level government officials perceived leadership at the national and regional levels as critical to ensure mainstreaming into strategic documents, such as a country's vision and economic development plans. Such leadership provides a concrete signal for policy-makers at lower administrative levels regarding the need for mainstreaming. Moreover, coordination at the regional level is important to ensure the integrity of transboundary environmental resources and ecosystems; in these cases, mainstreaming from the regional plans and strategies (e.g., Caribbean region, West Indies) could trickle down into national-level strategies. However, participants' feedback giving the highest score to this barrier (issue A5 in Tables 4 and 5) indicates that reaching national planning documents is not enough. The follow-through from the strategic level to policy development and implementation is often one of the biggest barriers for advancing mainstreaming. They indicated that in some cases-e.g., limits 
for shoreline development, use of agricultural pesticides - policy and related regulations are in place, but weak leadership hinders enforcement and compliance (possibly rooted in lack of capacities of the officers and/or corruption and bribes). Again, participants emphasized the importance multi-level approaches by suggesting that while regional institutions cannot implement national policy, they can provide regional guidance for policy development, helping to draft legislation and design implementation pathways.

\subsection{Insufficient Science and Policy Interaction to Facilitate EM}

One of the key challenges related to EM in the Caribbean appears to be a lack of research to guide the design of specific measures and policies that need be implemented in other sectors. Examples listed by the policy-makers on knowledge gaps included questions, such as what is the acceptable level of pollution given its impacts on aquatic ecosystems' health? What are the limits for water withdrawals and their seasonality to ensure biodiversity protection? What is an acceptable size for tourism facilities on the coast? Most of the policy-makers emphasized the importance of creating communication outputs (e.g., policy and technical briefs) that could help them understand the research findings and communicate them to their directors and higher-level policy-makers (see Table 4, issue B3). When discussing the role and use of information in policy, our results indicate that participants felt strongly, by giving a very high score to this barrier, that most of the research outcomes are complicated to interpret for policy-makers, and they do not provide clear guidance on needed actions (see issue B2, Tables 4 and 5).

Many participants perceived a key challenge for the above-mentioned barrier was related to data availability for monitoring environmental and co-related sectoral trends that could be used to frame policy choices. At the national and regional levels, participants had experience with monitoring impacts and trends on the state of the environment, but had less information related to monitoring the implications of development decisions for the environment, which can then be used to advocate the need for EM with up-to-date monitoring data and information. From a mainstreaming perspective, these monitoring efforts would need to be harmonized in the context of a country and/or region, which was described as an "overwhelming task" by the policy-makers consulted.

This mismatch between research outcomes and the knowledge and information needs of the policy process can be a barrier to enhance science-policy linkages. Participants engaged in policy-making at junior and medium levels of government perceived they lack the processes and/or tools to help them work with research findings and translate them into cross-sectoral decision-making and policy. At the same time, workshop participants also emphasized that research needs to be better targeted toward the policy process; for example, by listing potential policy recommendations to be further developed by policy-makers.

Other issues raised by interviewees and workshop participants relate to the timely availability of research outcomes; for example, they are not available at times of strategy and policy development, and policy reviews (see Table 4, B3).

Regional institutions - including academic networks - have significant opportunities to contribute to addressing some of these challenges. These institutions and networks can build on a number of assessments already completed, to increase their relevance for EM and to encourage better regional collaboration between researchers and policy-makers in identifying regional, national and subnational 
policy implications. Furthermore, participants suggested better coordination of published data and information at regional level so that policy-makers are aware of their existence and can use it to better inform the policy process.

\subsection{Ineffective Enabling Environment: Institutional and Organizational Barriers}

The third group of perceived barriers relates to institutional aspects that generally discourage collaboration and cooperation (Table 4, issues C1 to C4). During the workshop, participants shared relevant experience with their own bureaucratic processes that discourage cross-sectoral collaborations such as shared review of planned legislation and monitoring.

Most of the policy-makers' collaboration was perceived as a grey area within their departments and agencies. The lack of direct support fostering collaboration as part of regular policy processes was cited as a critical issue for advancing mainstreaming. Government officials in medium and junior levels of policy-making felt that this created uncertainty. They said they had limited their efforts to initiate collaboration because of concerns about disciplinary consequences, or simply because a lack of time gave lower priority to this issue. Frequently, this uncertainty was related to conflicts and competition at the higher ministerial level, where staff are not encouraged to reach out to ministries/institutions because of past challenges, such as perceived unequal budget allocations, mistreatment, lack of trust, and history of non-collaboration.

Lack of collaboration was linked primarily to leadership and budgetary challenges, including limited budgets for staff to engage in collaborative efforts and the potential need to share financial resources with other collaborating agencies (or split current funding). Both of these barriers were perceived to be highly significant by giving them a very high score during the participatory workshops (issues C3 and C4; Tables 4 and 5). These barriers also relate to so called "turf-ism" defined as a barrier created when agencies have limited interest in collaboration with other stakeholders - such as different government departments, academia and non-government agencies - because of a perceived threat of potential loss of leadership by the collaborating agency [10]. This is partly an issue of institutional culture, but also relates to the absence of guidelines on how mainstreaming processes can be initiated and how the power struggles between the agencies could be better handled. Many participants perceived that leadership at the level of regional organizations can emphasize multi-level coordination and collaboration by specifically requesting cross-sectoral participation in consultations, meetings and trainings. To also provide input for addressing barrier at the leadership level (Section 3.1; barriers A1-A4 in Table 4) regional agencies should focus on assisting with specific national issues, such as the development of a new country vision, revision of development policy, revision of tourism/agricultural policies; and when providing assistance with the former, ensure cross-sectoral collaboration serve as a template for actions at the national level.

\subsection{Quantity and Quality of Human Resources as Barrier to EM}

The last set of barriers relates to lack of capacity and skills to undertake mainstreaming efforts (Table 4, issues D1 to D4). A key barrier is the quantity (number of staff) and quality (knowledge, preparedness and skills) of human resources. Participants noted an increase in the number and complexity of tasks (and often a decrease in the number of staff) as a common national scenario in the 
public sector engaged in policy affecting the environment. The already busy work schedule of policy-makers and staff do not include space for activities requiring longer time horizons, like engaging in collaboration and mainstreaming. Participants and senior policy-makers interviewed felt that informal collaborations are more suited for their current schedule, as they are more flexible with adjustments and work better within the aforementioned unclear institutional guidelines. However, participants noted that such informal approaches lack commitment for overcoming challenges to advance EM, and integrating it into strategies, policies and actions.

Many workshop participants indicated that, while they had some understanding of linkages between their sector and the environment, working on mainstreaming in a practical way was a new experience, and they were not sure what types of outcomes to expect from an EM process. Consequently, they tend to rely on their sectoral knowledge, instead of being open to discussing broader cross-sectoral priorities (that could require significant changes in their sector). Moreover, the participants noted a lack of confidence regarding skills in leading larger multi-sectoral processes, with potentially challenging relationships amongst involved policy-makers and their departments/agencies.

Participants recognized building bottom-up "readiness" as a key part of mainstreaming, so that local government units responsible for on-the-ground implementation of government policies and projects are able to mainstream environmental priorities as part of the process. Participants stressed that regional institutions can play a capacity-building role by providing information to guide policy development, for awareness rising and to improve key stakeholders' knowledge of best practices for policy compliance and enforcement (e.g., instruments such as closed fishing seasons and limited use of agro-chemicals).

\section{Discussions}

This paper set out to demonstrate that regional organizations can provide targeted support to address barriers at the national and subnational levels to advance EM. While discussing these national and subnational barriers separately provides insights on potential specific actions to improve mainstreaming efforts, consideration needs to be given to the synergy and interactions of barriers at different levels. Here we discuss three issues that emerged as important from our results: bottom-up and top-down coordination, identifying synergies between barriers, and strategic opportunities at the regional levels to advance EM at the national and subnational levels.

\subsection{Mutli-Level Coordination Needs to Support Mainstreaming}

Our findings confirm earlier views [20,21] pointing that effective mainstreaming needs be coordinated simultaneously at vertical, hierarchical administrative levels within regional, national, and subnational institutions. Based on policy-makers' feedback, targeting mainstreaming efforts to policy-makers in general is not effective, as they have different roles that influence their opportunities for advancing mainstreaming, and, thus, have different capacity-building needs.

Although previous research $[4,5,15,16,30]$ suggests focusing on national level as entry point for mainstreaming, our results showed that a combined multi-level approach to strengthen capacities at the national, departmental/agency, and individual levels is needed prior to its implementation. In terms of implementing such a multi-level approach, [21] suggests that actors at each level need different policy learning opportunities postulated by their institutional and individual needs. The in-depth exploration on 
key barriers showed that regional agencies can play a considerable role in building capacities for mainstreaming by senior policy-makers, through providing them with specific tools and examples of linkages between the environment and economic/social issues. This is especially relevant in the studied Caribbean context. In the region, current challenges such as droughts, water quality, and availability, and tourism development initiatives are shared across the countries. Providing information on potential environmental challenges of development, and measures to address them in a brief and accessible form furnishes arguments that policy-makers need to gain support from other departments and agencies. A crucial step here is to reach out to senior policy-makers at times when national strategies and programs are being developed, so they can ensure that cross-sectoral views are included. This could then trigger cross-sectoral strategy development at the lower levels.

On the other hand, policy-makers at lower levels of the administrative hierarchy need to supply their leaders with salient information, and initiate necessary inter-institutional collaborative processes. From this perspective, staff of ministries and government agencies play a crucial role in advancing mainstreaming, as they become a "physical" science-policy bridge to directors/senior-level policy-makers; their technical background enables understanding of existing information and knowledge, and available choices, which they can communicate upwards.

Our findings suggest that there are limits to seeing the sole major barrier to implementation as support at the leadership level and improved political will; it may not result in action if other levels of the policy process are not ready. Enhancing the mainstreaming skills and preparedness of policy-makers creates a bottom-up basis within agencies and ministries that could provide an additional push for mainstreaming and coordination, with top-down guidance from the regional and national levels.

Key capacity-building efforts led by regional institutions to advance multi-level interactions in the Caribbean region and elsewhere could include:

- Working with senior policy-makers — including directors and ministers at the national level — to share experiences, best practices and communication tools; such instruments could be built into their portfolios, and used to negotiate with other ministries, departments, and investors.

- Providing leading practice examples of how to develop cross-sectoral national visions and strategies that account for environmental challenges embodied with development priorities; this should also include information on processes that can be used to develop collaborative national strategies with different departments and other stakeholders.

- Best practice examples and support to integrate collaboration and mainstreaming needs at departmental or agency levels, organizing capacity-building activities to "learn how to make them work".

\subsection{Synergies between Barriers}

Our research findings show connections between institutional barriers and capacities of policy-makers; thus, organizational cultures - and a lack of formal/informal rules for collaboration - limit the capacities of policy-makers to engage with their peers and other stakeholders. This also relates to current work structures and staff performance reviews that fail to value engagements in collaboration necessary for EM (see Table 4). It seems that recognizing such behavior at all levels, from regional to subnational (both within and between government agencies), is crucial for strengthening foundations for EM. 
Another critical factor is developing a strong link between available scientific information to support mainstreaming, leadership and capacities of policy-makers. In discussing the role and use of information in policy, [21] call attention to the unfulfilled "expectation of scientists and activists in the environmental domain that scientific information will be transformed into clear messages that will instruct decision-makers in an unambiguous obvious fashion"; our results show that to be the case (see issue B2, Table 4).While EM is perceived as less important compared to economic development, one key factor seen to contribute to this issue is the lack of targeted science-based evidence to illustrate the negative environmental impacts of development priorities choices. Senior policy-makers interviewed suggested that timely, high-quality research outcomes produced in a policy-relevant context are needed for EM at the national level. Furthermore, such information was also perceived as necessary to guide the next steps in EM, going beyond integration, to designing policies and management options and ensuring their implementation. At this level, science-based outcomes (data, information, and knowledge) can provide much-needed guidance on, for instance, thresholds for zoning, use of chemicals, water- and land-management practices. This view is aligned with a review on environmental information activity undertaken in Australia [7] that pointed toward a lack of strategic and targeted information as the problem, rather than a lack of information; many Australian agencies participating in the review provided examples where the government is seemingly awash in environmental information for which the policy analysis layer is either unclear or absent.

In the context of these barriers, government officials engaged in policy-making need improved capacities to synthesize research knowledge outcomes to support senior bureaucrats when negotiating the role of EM in the development agenda. Given the intertwined nature of the barriers that are relevant for a number of countries in the Caribbean and likely elsewhere, regional institutions can assist in capacity-building at the national and subnational levels by:

- Producing guidelines for policy-makers on targeted skills' development for mainstreaming and cross-sectoral collaborations, on effective ways to communicate mainstreaming benefits to senior decision-makers, and on collaboration with local stakeholders and scientists. Such skills are key to advancing mainstreaming, and they are often not a core part of the education that policy-makers receive.

- Improving communication between policy-makers and scientists on policy-related needs to address environmental challenges at national and regional levels, and to target the capacities of research institutes and academia by prioritizing knowledge production in these key areas.

\subsection{Strategic Regional Leadership to Advance EM at the National Level}

The previous sections presented key needs for regional leadership prompted by common barriers for $\mathrm{EM}$ at the horizontal and vertical levels. Beyond this rationale, it is important to stress that improving EM in the Caribbean region is crucial to ensuring the integrity of transboundary environmental resources and ecosystems [27,28]. This can only be achieved if countries better coordinate efforts to maintain environmental quality, and its integration into development decisions. Interviewees and workshop participants indicated that regional institutions and agencies still have a relatively strong weight at the national level when prioritizing certain issues. 
Regional agencies can exercise leadership by providing support for EM across scales and barriers; As indicated earlier, signaling to senior and junior policy-makers (through the involved key national representatives in EM) is important to create confidence in collaboration at the lower levels. For example, regional initiatives focusing on development challenges like tourism, agriculture and fisheries, and finance and budgeting bring together cross-sectoral experts from the participating countries.

Another key role is in terms of bringing together science and data across the region to address limited capacities that characterize most SIDS. National policy-makers of the Caribbean frequently indicated scarce human resources available for EM. Regardless future improvements, regional and international organizations can play an important knowledge and information brokering role in support of policy-making, stressing the importance of EM at the regional level. Most policy-makers felt they lacked credible and understandable scientific outputs that could be used to initiate effective mainstreaming efforts, as they tend to get stalled for lack of evidence, lack of ideas about what can be done and lack of baseline assessments and monitoring to assess progress. Especially for SIDS, effective EM presents enormous data, information, knowledge and policy requirements that may not be possible to cover in all concerned areas of the environment.

There are windows of opportunity for regional and perhaps global-level collaboration, to actively support targeted research, assisting policy-makers in illustrating linkages between decisions (e.g., environmental, development, etc.) and policy implications, so that policy-makers are better equipped to bridge research into policy domains. Main capacity-building efforts relevant for regions beyond the Caribbean could be listed as follows:

- Raising EM in regional forums when sectoral and cross-sectoral issues and challenges are discussed or addressed.

- Encourage regional, policy-relevant research exchanges and shared conduct on areas relevant to the SIDS in the Caribbean and elsewhere, to improve knowledge within countries about key priority areas for EM.

- Improve monitoring and data collection systems at the regional level to better connect national and subnational data and information, and thus improve monitoring impacts of policy on environmental trends.

\section{Concluding Remarks: Future Research Needs}

Our findings suggest that success in mainstreaming in the Caribbean region will depend on the extent to which policy-makers have opportunities for intra-regional collaboration and experience-sharing. Capacities need to be built for integrated policy planning across the whole of government in which not only governance of the environment (e.g., environmental policy and its national implementation), but also governance for the environment (by incorporating environmental concerns into other policy-relevant domains) is realized.

While there has been considerable research on national-level barriers, additional research and policy need to focus on the regional level, including detailed reviews of regional programs to ensure EM and cross-sectoral collaborations are effectively reinforced there; developing guidance, principles, and examples of national and sectoral strategies, and policies with EM to assist senior and junior bureaucrats; creating a knowledge-management system to bring together science-based information that is accessible 
to different countries in the region, and identifying specific types of research outcomes relevant for EM and integrating them into regional and national research initiatives.

\section{Acknowledgments}

The authors would like to thank the participants of the interviews and workshops for their valuable inputs and colleagues from CARICOM and IISD for their assistance with this study. The authors are also thankful to two anonymous reviewers whose critical comments improved the quality of the paper.

\section{Author Contributions}

The individual contribution and responsibilities of the authors were as follows: Livia Bizikova: research design, grant holder of research financing, participation in the interviews, workshops and related data collection, data analysis, supervision of data collection and analysis, article writing. Graciela Metternicht: literature review, participation, data analysis, article writing and formatting. Therese Yarde: inputs to the research design, participation in the workshops and related data collection, article writing and review.

\section{Conflicts of Interest}

The authors declare no conflict of interest.

\section{References}

1. Kok, M.T.J.; de Coninck, H.C. Widening the Scope of Policies to Address Climate Change: Directions for Mainstreaming. Environ. Sci. Policy 2007, 10, 587-599.

2. Bojö, J.; Green, K.; Kishore, S.; Pilapitiya, S.; Reddy, R.C. Environment in Poverty Reduction Strategies and Poverty Reduction Support Credits (Working Paper No. 102); World Bank: Washington, DC, USA, 2004.

3. Jakubik, M. Exploring the knowledge landscape: Four emerging views of knowledge. J. Knowl. Manag. 2007, 11, 6-19.

4. United Nations Environment Programme. Mainstreaming Poverty-Environment Linkages into Development Planning: A Handbook for Practitioners; UNDP-UNEP Poverty-Environment Facility: Nairobi, Kenya, 2009.

5. Dalal-Clayton, D.B.; Bass, S. The Challenges of Environmental Mainstreaming. No.1 of Environmental Governance Series; International Institute for Environment and Development: London, UK, 2009.

6. United Nations Environment Programme. Latin America and the Caribbean: Environment Outlook; UNEP: Panama City, Panama, 2010.

7. Morton, S.; Tinney, A. Independent Review of Australian Government Environmental Information Activity: Final Report; SDEWPaC: Canberra, Australia, 2012.

8. Mainstreaming and Adaptation to Climate Change (MACC). 2013. Available online: http://www.caribbeanclimate.bz/closed-projects/2004-2007-mainstreaming-adaptation-to-climatechange-macc.html (accessed on 11 July 2014). 
9. United Nations Environment Programme. Global Environment Outlook 5: GEO5: Environment for the Future We Want, 5th ed.; UNEP: Nairobi, Kenya, 2012.

10. CANARI. Report on Caribbean Component of IIED's User Guide to Effective Tools and Methods for Integrating Environment and Development. 2008. Available online: http://www.environmentalmainstreaming.org/Country\%20Surveys/cs_carribean.html (accessed on 11 July 2014).

11. Lasco, R.; Pulhin, F.; Jaranilla-Sanchez, P.; Delfino, R.; Gerpacio, R.; Garcia, K. Mainstreaming Adaptation in Developing Countries: The Case of the Philippines. Clim. Dev. 2009, 1, 130-146.

12. Maes, J.; Hauck, J.; Paracchini, M.; Ratamaki, O.; Hutchins, M.; Termansen, M.; Furman, E.; Perez-Soba, M.; Braat, L.; Bidoglio, G. Mainstreaming Ecosystem Services into EU Policy. Curr. Opin. Environ. Sustain. 2013, 5, 128-134.

13. Sietz, D.; Boschutz, M.; Klein, R. Mainstreaming climate adaptation in to development assistance: rationale, institutional barriers and opportunities in Mozambique. Environ. Sci. Policy 2011, 14, 493-502.

14. Halpern, B.S.; Walbridge, S.; Selkoe, K.A.; Kappel, C.V.; Micheli, F.; D’Agrosa, C.; Bruno, J.F.; Casey, K.S.; Ebert, C.; Fox, H.E.; et al. A Global Map of Human Impact on Marine Ecosystems. Science 2008, 319, 948-952.

15. Soussan, J. Making Mainstreaming Work-An Analytical Framework, Guidelines and Checklist for the Mainstreaming of Marine and Coastal Issues into National Planning and Budgetary Processes; UNEP/GPA Coordination Office: The Hague, The Netherlands, 2007.

16. Nunan, F.; Campbell, A.; Foster, E.A. Environmental mainstreaming: The organisational challenges of policy integration. Public Adm. Dev. 2012, 32, 262-277.

17. Morrison, T.; Lane M. What "Whole-of-Government" approach means for Environmental Policy and Management: An Analyses of the Connecting Government Initiative. Aust. J. Environ. Manag. 2005, 12, 47-54.

18. Integra. Environmental Mainstreaming: A User Guide to Tools and Tactics. 2008. Available online: http://www.environmental-mainstreaming.org/documents/Country\%20Survey\%20Report\%20\%20Central\%20and\%20Eastern\%20Europe.pdf (accessed on 13 October 2015).

19. Mainstreaming and Adaptation to Climate Change (MACC). 2005. Available online: http://www.nepa.gov.jm/neec/climate_change_portal/documents/climate\%20change\%20journalis m\%20handbook.pdf (accessed on 10 October 2015).

20. Persson, A.; Klein, R.J.T. Mainstreaming Adaptation into Official Development Assistance: Integration of Long-Term Climate Concerns and Short-Term Development Needs. 2008. Available online: http://userpage.fu-berlin.de/ffu/akumwelt/bc2008/papers/bc2008_71_Person-Klein.pdf. (accessed on 15 December 2014).

21. Dovers, S.; Hussey, K. Environment and Sustainability: A Policy Handbook, 2nd ed.; The Federation Press: Sydney, Australia, 2013.

22. Schout A.; Jordan, A. The European Union's Governance Ambitions and Its Administrative Capacities. J. Eur. Public Policy 2008, 7, 957-974.

23. Brown, D. Institutional Development in Small States: Evidence from the Commonwealth Caribbean. Adm. Cult. 2010, 11, 44-65. 
24. Trotman A.; Gordon, R.M.; Hutchinson, S.D.; Singh, R.; McRae-Smith, D. Policy Responses to GEC Impacts on Food Availability and Affordability in the Caribbean Community. Environ. Sci. Policy 2009, 12, 529-541.

25. Harvey, C.; Komar, O.; Chazdon, R.; Ferguson, B.G.; Finegan, B.; Griffith, D.M.; Martínez-Ramos, M.; Morales, H.; Nigh, R.; Soto-Pinto, L.; et al. Integrating Agricultural Landscapes with Biodiversity Conservation in the Mesoamerican Hotspot. Conserv. Biol. 2008, 22, 8-15.

26. UN Environment Programme. Climate Change in The Caribbean and the challenge of adaptation. 2008. Available online: http://www.pnuma.org/deat1/pdf/Climate_Change_in_the_Caribbean_ Final_LOW20oct.pdf. (accessed on 11 July 2014).

27. UN Environment Programme. GEO SIDS: Small Island Developing States Outlook. 2014. Available online: http://apps.unep.org/publications/pmtdocuments/-Global\%20Environment\%20 Outlook:\%20small\%20island\%20developing\%20states-2014GEO_SIDS_final.pdf (accessed on 11 July 2014).

28. Ford, J.R.D.; dell'Aquilla, C.; Conforti, P. Agricultural Trade Policy and Food Security in the Caribbean: Structural Issues. In Multilateral Negotiations and Competitiveness; Food and Agricultural Organization: Quebec City, QC, Canada, 2007.

29. Atkinson R.; Flint, J. Accessing Hidden and Hard-To-Reach Populations: Snowball Research Strategies. 2001. Available online: http://sru.soc.surrey.ac.uk/SRU33.pdf (accessed on 15 December 2015).

30. Benson, E.; Forbes, A.; Korkeakoski, M.; Latif, R.; Lham, D. Environment and climate mainstreaming: Challenges and successes. Dev. Pract. 2014, 24, 605-614.

31. Reed, M.S. Stakeholder Participation for Environmental Management: A Literature Review. Biol. Conserv. 2008, 141, 2417-2431.

32. Coffey A.; Atkinson, P. Making Sense of Qualitative Data; Sage: Thousand Oaks, CA, USA, 1996.

(C) 2015 by the authors; licensee MDPI, Basel, Switzerland. This article is an open access article distributed under the terms and conditions of the Creative Commons Attribution license (http://creativecommons.org/licenses/by/4.0/). 